\title{
ESTUDO DO DERIVADO DO ÓLEO DE RICINUS COMMUNIS L. (MAMONA) COMO AGENTE BIOCIDA E REDUTOR DA VISCOSIDADE PRODUZIDA POR LEUCONOSTOC MESENTEROIDES EM INDÚSTRIAS SUCROALCOOLEIRAS
}

\author{
M.A. Messetti ${ }^{1}$, A.M. dos Santos ${ }^{1}$, D.F de Angelis ${ }^{1}$, G.O. Chierice ${ }^{2}$, S. Claro Neto ${ }^{2}$ \\ ${ }^{1}$ Universidade Estadual Paulista, Departamento de Bioquímica e Microbiologia, CP 199, CEP 13506-900, Rio \\ Claro,SP, Brasil.E-mail:mari_messetti@ig.com.br
}

\section{RESUMO}

Das sementes da mamona extrai-se o óleo de rícino, utilizado in natura ou em sua forma modificada nas áreas médica, farmacêutica e industrial. Um de seus derivados químicos - o Poliquilgerm $^{\circledR}$ - evidencia propriedades antifúngicas sobre Candida albicans e bacteriostática/ bactericida sobre Escherichia coli no nível de 99,9\%. Considerando-se essas propriedades, aplicouse o Poliquilgerm ${ }^{\circledR}$ em culturas de Leuconostoc mesenteroides, uma das espécies de bactéria contaminante dos mostos em indústrias sucroalcooleiras. Esta bactéria quando presente em mostos produz além do ácido láctico, a dextrana, que é um polímero da glicose que aumenta a viscosidade dos fluidos dos processos. No presente trabalho avaliou-se o efeito de diferentes concentrações do Poliquilgerm ${ }^{\circledast}$ sobre a viscosidade produzida por L. mesenteroides em diferentes meios de cultivo, condições de $\mathrm{pH}$, e temperatura. Verificou-se 20,56\% de diminuição da viscosidade quando se utilizou 1,0\% do produto, além da inibição do crescimento da bactéria após 20 horas em contato com 1,0 e $0,2 \%$ de Poliquilgerm ${ }^{\circledR}$. L. mesenteroides apresentou melhor crescimento em valores de $\mathrm{pH} 6,0$, tanto a 28 como a $33^{\circ} \mathrm{C}$, evidenciado pela maior produção de biomassa. Além disso, em meio de cultura neste $\mathrm{pH}$ verificou-se maior porcentagem de diminuição da viscosidade em ambas as concentrações utilizadas. Estas mesmas concentrações alcançaram até $100 \%$ de diminuição das UFC/mL após 24 horas em contato com o produto, evidenciado por quantificação da biomassa e confirmado mediante plaqueamento pela técnica "Pour Plate".

PALAVRAS-CHAVE: Poliquilgerm ${ }^{\circledR}$, Leuconostoc mesenteroides, mamona, viscosidade.

\begin{abstract}
STUDY OF A RICINUS COMMUNIS L. (CASTOR OIL) DERIVATIVE AS A BIOCIDAL AGENT AND VISCOSITY REDUCER ON LEUCONOSTOC MESENTEROIDES IN THE SUGAR AND ALCOHOL INDUSTRIES. Castor-oil, extracted from seeds of Ricinus communis L., is normally used in natura or in its modified form in the medical, pharmaceutical and industrial areas. One of its chemical derivates - Poliquilgerm ${ }^{\circledR}$ - has shown antifungal properties on Candida albicans, and bacteriostatic/bactericide effects on Escherichia coli reaching $99.9 \%$. Considering these features, in the present study Poliquilgerm ${ }^{\circledR}$ was applied in cultures of Leuconostoc mesenteroides, a frequent contaminant bacterium of musts in the sugar and alcohol industries. This bacterium, when a contaminant of must, produces lactic acid as well as dextran, a polymer of glucose which may increase the viscosity of fluids in the operation. The present study evaluated the effect of different concentrations of Poliquilgerm ${ }^{\circledR}$ on viscosity produced by L. mesenteroides cultures under different conditions of various culture media, $\mathrm{pH}$ and temperature. A $20.56 \%$ decrease in viscosity was verified when $1.0 \%$ of the product was used, and bacterium growth inhibition after 20 hours in media with 1.0 and $0.2 \%$ of Poliquilgerm ${ }^{\circledR}$. L. mesenteroides showed a higher growth rate in $\mathrm{pH} 6.0$, at both 28 and $33^{\circ} \mathrm{C}$, evidenced by greater biomass production. Also, in the culture media at this $\mathrm{pH}$ a greater decrease in viscosity percentages was verified at both concentrations used. The media with these same concentrations reached up to $100 \%$ decrease of UFC $/ \mathrm{mL}$ after 24 hours in the presence of the product, observed by biomass quantification and confirmed by the Pour Plate technique.
\end{abstract}

KEY WORDS: Poliquilgerm ${ }^{\circledR}$, Leuconostoc mesenteroides, castor oil, viscosity.

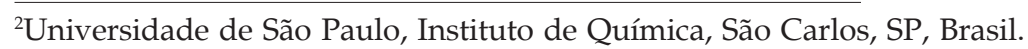




\section{INTRODUÇÃO}

A fermentação etanólica no Brasil processa-se em condições não assépticas, sendo frequente a contaminação por bactérias. Esses contaminantes constituem um dos maiores problemas, tanto operacionais como econômicos na indústria. A situação nesta etapa agrava-se com o reciclo de células de levedura para aumentar a produtividade, pois também ocorreconcentração das bactérias. A contaminação bacteriana origina-se durante as operações de transferência da cana-de-açúcar do campo até a unidade industrial, envolvendo corte, carregamento, transporte, descarregamento e armazenamento da matéria-prima (Rosales, 1989).

São as bactérias Gram-positivas que mais induzem problemas no processo fermentativo, provavelmente devido ao fato da parede celular das bactérias Gram-negativas ser rica em lipídeos, os quais são facilmente solubilizados em álcool, presente nas dornas de fermentação. Os trabalhos de RoDinI (1985) e GALLO (1989) comprovaram a dominância das bactérias Gram-positivas. As bactérias contaminantes concorrem com a levedura Saccharomyces cerevisiae pelo açúcar disponível, realizando fermentações secundárias que resultam na produção de outros subprodutos que não o álcool. Estes subprodutos podem alterar características físico-químicas como $\mathrm{pH}$, acidez, viscosidade; bem como a morfologia das leveduras, induzindo a floculação e à deformação celular devido à presença de gomas e ácidos orgânicos, respectivamente (ROSALES, 1989).

Leuconostoc mesenteroides é um dos contaminantes mais frequentesno processo defermentaçãoindustrial para produção de etanol, pois produz, além do ácido láctico, a dextrana. A dextrana manifesta-se na forma de uma massa gelatinosa transparente conhecida na indústria como "goma" ou "canjica"; causando diversos prejuízos físicos devido ao aumento da viscosidadedomosto, com consequente entupimento dos trocadores de calor, tubulações e centrífugas, além de possíveis danos para a levedura. Deacordo com Holtetal. (1986), o gênero Leuconostoc é formado por bactérias Gram-positivas, anaeróbias facultativas. Sua sensibilidade a antibióticos e drogasédesconhecida visto que nenhuma espécie é confirmada como patogênica. A síntese de dextrana ocorre a partir de uma enzima extracelular, uma glicosiltransferase (dextranasacarase), que possui a propriedade de atuar sobre a molécula de sacarose, liberando a frutose e transferindo a molécula de glicose a uma molécula receptora, no caso moléculas de dextrana em expansão.

Muitas técnicas vêm sendo utilizadas para controlar a contaminação bacteriana, como a aplicação de ácido sulfúrico para baixar o $\mathrm{pH}$ e biocidas que favorecem a levedura. Rotineiramente utiliza-se o ácido sulfúrico após a centrifugação do fermento e antesdeleser submetidoa uma novaetapa fermentativa (Silva FilHo, 1993). A acidez do meioéadequada para o desenvolvimento da levedura ( $\mathrm{pH} 4,0-5,0)$, sendo prejudicial à maioria das bactérias contaminantes. Assim, a aplicação deácidoé empregada como medida preventiva e controladora de infecções, embora valores de $\mathrm{pH}$ muito baixos possam afetar a levedura (ROSALES, 1989). Segundo GUERRA (1995), a utilização frequentedeácido sulfúrico pelas destilarias no intuito de combater as contaminações bacterianas pode gerar alguns problemas, como aqueles associados à qualidade do álcool, morte das leveduras, corrosão nos equipamentos, segurança pessoal einstabilidade do sistema. Como substâncias alternativas são utilizados antibióticos e biocidas para o controle das infecções.

O óleo de mamona destaca-se economicamente pela versatilidade química no ramo industrial. Segundo Chierice; Claro-Neto (2001), este óleo é um triglicerídeo rico em ácido ricinoleico, presente em $89,5 \%$ de sua composição. A presença de hidroxila, insaturação e carboxila - que são três grupos funcionais altamente reativos no ácido ricinoleico - faz com que este óleo possa ser submetido a diversos processos químicos para a obtenção de subprodutos utilizados nas áreas farmacêutica, cosmética, de lubrificantes, polímeros e produção de biodiesel etc. Os polímeros de ácidos graxos são utilizados na elaboração de próteses e implantes, substituindo o silicone e outros materiais em cirurgias ósseas e de próstata. Em 1984, o Grupo de Química Analítica e Tecnologia de Polímeros (GQATP) do Instituto de Química da Universidade deSão Paulo, em São Carlos, desenvolveu novos polióis derivados do óleo da mamona (IGNÁcio, 1995 apud ReZENDE et al., 2001). Dentre os polióis desenvolvidos, o Endoquil ${ }^{\circledR}$ tem sido aplicado como bactericida na área odontológica, sendo utilizado em substituição ao hipoclorito de sódio para irrigação de canais e apresentando atividade antimicrobiana contra bactérias Gram-positivas (FERREIRA, 1996, LeONARDO et al.,2001). Ogrupo GQATP sintetizou outros produtos com aplicações na área médica, como a poliuretana partindo de polióis derivados do óleo de mamona para implantes em aves (Bolson et al., 2005; ReZEnde et al., 2001). Outro poliol, o Poliquilgerm ${ }^{\circledR}$, foi avaliado por BerTOLETTI et al. (2004) e MessetTI et al. (2005), que verificaram in vitro efeito microbiostático sobre Candida albicans e Escherichia coli CCT 1457. OLIVEIRA (2005), estudando a decomposição de sacarose por hidrólise, utilizou uma mistura deésteres derivados doóleo de mamona e verificou a sua capacidade hidrolítica na formação de glicose e frutose. Assim, acredita-se que os ésteres atuem como "transferidores" deágua para a molécula de sacarose, catalisando a reação hidrolítica ao 
romper a ligação glicosídica, que também está presente na parede celular das bactérias.

Opresente estudo propõe a utilização do derivado doóleo de mamona-Poliquilgerm ${ }^{\circledR}$ - comoagente biocida no controle das contaminações pela bactéria L. mesenteroides em indústrias sucro-alcooleiras, visando a diminuição da viscosidade do mosto contaminado. Para tanto, avaliou-se o efeito de diferentes concentrações de Poliquilgerm ${ }^{\circledR}$ sobre $L$. mesenteroides, com relação às mudanças de viscosidade dos meios de cultura e a verificação do crescimento da bactéria.

\section{MATERIALEMÉTODOS}

A bactéria Leuconostocmesenteroides (B512) foi inoculada em meio de cultura MAYeux; Colmer (1961) para produção de goma e incubada por 24 horas a 30 $\pm 1^{\circ} \mathrm{C}$. A partir deste inóculo, a bactéria foi cultivada em erlenmeyers de $125 \mathrm{~mL}$ contendo $50 \mathrm{~mL}$ do mesmo meio de cultura, no qual foram acrescidos diferentes concentrações de Poliquilgerm ${ }^{\circledR}$. No primeiro experimento, foram utilizadas as concentrações 2,0 e 1,0\%. Nos experimentos seguintes, optou-se por manter a concentração 1,0\% e avaliar uma concentração mais baixa do produto, no caso $0,2 \%$. As culturas e os controles (contendo apenas meio de cultura) foram mantidos em "shaker" a $100 \mathrm{rpm}$, na temperatura de $30 \pm 1^{\circ} \mathrm{C}$ por 24 horas. Decorrido o tempo de cultivo, mediu-se a viscosidade utilizando-se viscosímetro de Cannon-Fenske, a $21 \pm 1^{\circ} \mathrm{C}$. O crescimento de $L$. mesenteroides, na ausência e presença de 1,0 e $0,2 \%$ de Poliquilgerm ${ }^{\circledR}$, foi verificado por meio de espectrofotometria, mediantemedidas deabsorbância a $\lambda=540 \mathrm{~nm}$ nos tempos $0,6,20$ e 26 horas.

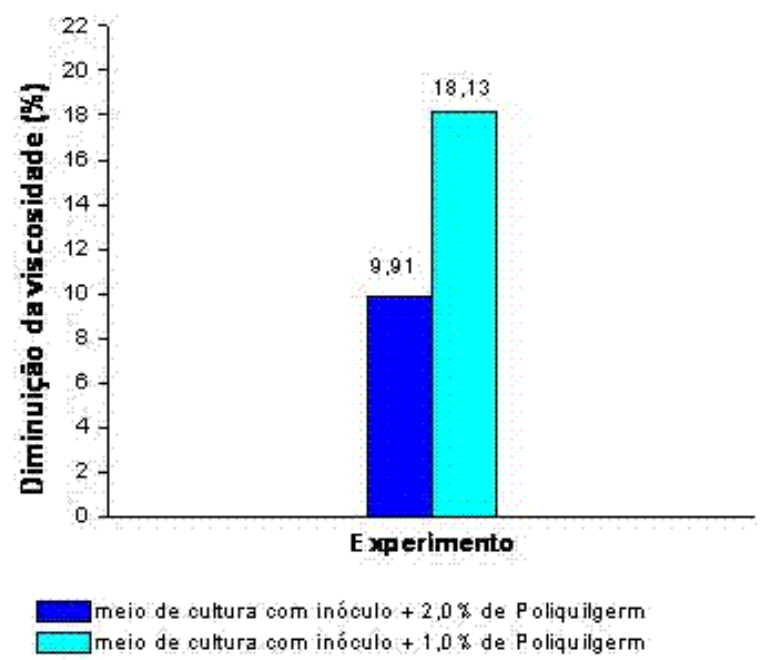

Fig. 1 - Porcentagem de diminuição da viscosidade das culturas de Leuconostoc mesenteroides acrescidas de 1,0 e 2,0\% de Poliquilgerm ${ }^{\circledR}$.
Em etapa posterior, preparou-se meio de caldo de cana suplementado com nutrientes (CSN) nos pHs 3,$0 ; 4,0 ; 5,0$ e 6,0, onde adicionou-se 0,2 e 1,0\% de Poliquilgerm ${ }^{\circledR}$, na ausência e presença da cultura de L. mesenteroides. Os controles eas culturas foram incubados em "shaker" a $100 \mathrm{rpm}$ nas temperaturas de 33 $\pm 1^{\circ} \mathrm{Ce} 28 \pm 1^{\circ} \mathrm{C}$ por 24 horas. Em seguida, mediu-se a viscosidade utilizando-se viscosímetro de CannonFenske a $21 \pm 1^{\circ} \mathrm{C}$, e efetuou-se a verificação do crescimento da cultura mediante análise da biomassa.

Todos os experimentos foram realizados em triplicata e as análises estatísticas efetuadas através do software The SAS System 9.1, utilizando-se análises de variância (ANOVA) com modelos fatoriais e teste de Tukey, com nível de significância de 0,05.

\section{RESULTADOSEDISCUSSÃO}

Atividade do Poliquilgerm ${ }^{\circledR}$ sobre culturas de $L$. mesenteroides, em meio Mayeux e Colmer.

Quantificação comparativa da viscosidade

A viscosidade das culturas de L. mesenteroides diminuiu após 24 horas em contato com o produto, e a porcentagem de diminuição foi calculada combasena viscosidade das amostras controle. No primeiro experimento houve $18,13 \%$ de diminuição da viscosidade da cultura quandose adicionou 1,0\% de Poliquilgerm ${ }^{\circledR}$ e $9,91 \%$ quando foi adicionado $2,0 \%$ (Fig. 1 ).

No segundo e terceiro experimentos, realizados em concentrações mais baixas do produto, verificouse 20,56 e $13,92 \%$ de diminuição da viscosidade da cultura quando adicionou-se $1,0 \%$ de Poliquilgerm ${ }^{\circledR}$; e 16,90 e $8,97 \%$ quando foi adicionado $0,2 \%$, respectivamente(Fig. 2).

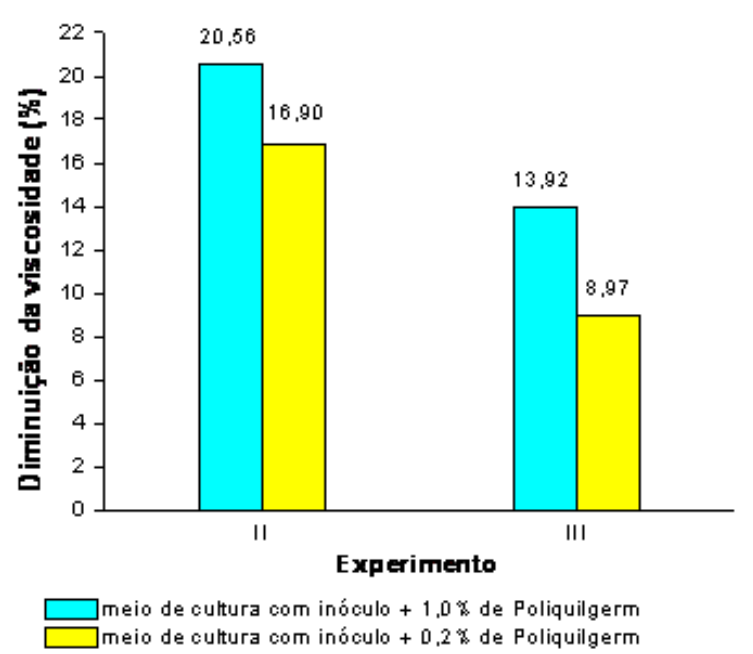

Fig. 2 - Porcentagem de diminuição da viscosidade das culturas de Leuconostoc mesenteroides acrescidas de 1,0 e $0,2 \%$ de Poliquilgerm ${ }^{\circledR}$. 
As concentrações 0,$2 ; 1,0$ e 2,0\% do produto não diferiram estatisticamente entre si. Entretanto, a concentração $1,0 \%$ dePoliquilgerm ${ }^{\circledast}$ foi a que apresentou as maiores porcentagens em diminuição da viscosidade. Pode-se concluir por meio desta análise que a adição de Poliquilgerm ${ }^{\circledR}$ nas culturas de $L$. mesenteroides induz a diminuição da viscosidade do meio, independente da dosagem utilizada.

A viscosidade causada por bactérias lácteas nos fluidos dos processos industriais assume importância quando estes devem ser agitados ou transferidos dos reatores para outros locais na indústria. A presença de alta viscosidade torna os processos energeticamente onerosos e isto reflete no custo geral dos produtos.

Crescimento da cultura de L. mesenteroides mediante quantificação da absorbância

A análise por espectrofotometria na região do visível $(\lambda=540 \mathrm{~nm})$ nos intervalos $0 ; 6$; 20 e 26 horas mostrou diminuição do crescimento do micro-organismo de $53,86,67,59$ e $56,56 \%$, respectivamente, após 6,20 e 26 horas em contato com $0,2 \%$ dePoliquilgerm ${ }^{\circledR}$. Quandoem contato com $1,0 \%$ de Poliquilgerm ${ }^{\circledast}$, verificou-se diminuição do crescimento do micro-organismo de 22,39e 17,97\%, respectivamente após 20 e 26 horas (Fig. 3). A maior diminuição ocorreu em 20 horas para ambas as concentrações do produto, sendoquea menor concentração dePoliquilgerm ${ }^{\circledast}(0,2 \%)$ mostrou-semais eficiente para promoverocontrolede L. mesenteroides. Segundo Holt et al. (1986), a sensibilidade do gênero Leuconostoc a antibióticos e drogas é desconhecida, visto quenenhuma espécieéconfirmada como patogênica.

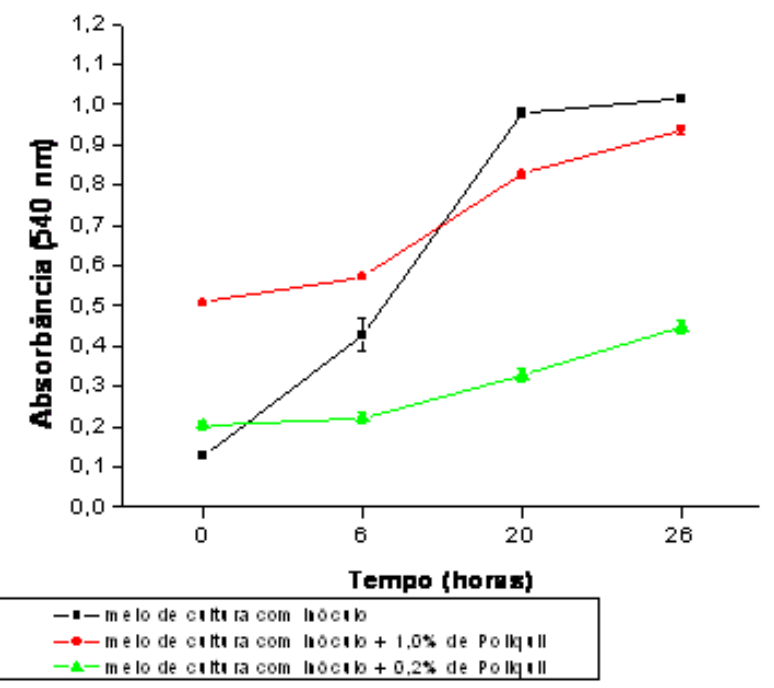

Fig. 3 - Quantificação da absorbância nas culturas de Leuconostoc mesenteroides acrescidas de 1,0 e 0,2\% de Poliquilgerm ${ }^{\circledR}$.
A análise de variância mostrou que todas as variáveis analisadas apresentaram-se estatisticamente significativas. Os valores de absorbância nas concentrações de 0,0; 0,2 e 1,0\% diferiram entre si. A maior média dos valores de absorbância foi obtida na ausência do produto $(0,5798 \mathrm{~nm})$, e a menor média na presença de $0,2 \%$ dePoliquilgerm ${ }^{\circledR}(0,1560 \mathrm{~nm})$. Como a medida de absorbância por espectrofotometria é indicativa de crescimento de micro-organismos, estes resultados mostram o maior crescimento de $L$. mesenteroides na ausência do produto. Com a adição de $0,2 \%$ de Poliquilgerm ${ }^{\circledR}$ registrou-se menor crescimento do micro-organismo, indicando ação inibitória do produto adicionado quando presente em menor concentração. Os valores de absorbância também diferiram estatisticamente em relação ao tempo de incubação. A maior média de absorbância e, consequentemente o maior crescimento de $L$. mesenteroides, ocorreu no tempo de 26 horas. Verificou-se que o crescimento da bactéria ocorreu gradativamente ao longo do tempo, condiçãonormal na curva de crescimento dos micro-organismos. A presença ou ausência do inóculo apresentou resultado estatisticamente significativo para a variável absorbância, sendo que a maior média foi obtida na presença do inóculo.

É bastante frequente a utilização do ácido sulfúrico, muitas vezes combinado com antibióticos, para combater a contaminaçãonas dornas de fermentação de indústrias sucroalcooleiras. Os baixos valores de $\mathrm{pH}$ (cerca de 2,0 a 3,0) podem diminuir a viabilidade celular da levedura. Quanto maior o tempo de exposição, que varia entre 0,5 a 2 horas, maior o impacto no metabolismo da levedura (LUDWIG, 1998). STUPIELLO (1993) em seu trabalho estudou os agentes antimicrobianos mais utilizados e seu modo de ação sobre bactérias Gram positivas. Como biocidas químicos, a autora encontrou fenol e compostos fenólicos, álcoois, halogênicos e halogenados, metais pesados e seus compostos, corantes, detergentes, composto de amônia quaternária, aldeídos e agentes gasosos. Os antibióticos mais utilizados nos processos fermentativos foram tetraciclina, cloranfenicol, penicilina e virginiamicina.

Oliva-Neto; YокоYa (2001) avaliaram diversos compostos antimicrobianos sobre Saccharomyces cerevisiae, Lactobacillus fermentum e Leuconostoc mesenteroides, dentre eles sulfito, nitrito, sulfato de cobre, penicilina $V$ ácida e clindamicina. Vários destes biocidas afetaram seriamente o crescimento de $S$. cerevisiae, nas dosagens similares àquelas que inibiram as bactérias. Os autores concluem que estes produtos deveriam ser evitados ou usados somente em condições especiais; e que para esta etapa o controle de contaminantes por antibióticos é mais efetivo. MENEGHIN et al. (2007) avaliaram o dióxido de cloro 
como biocida alternativo sobre o fermento: Bacillus subtilis, Leuconostoc mesenteroides, Lactobacillus plantarum, Lactobacillusfermentum, comparandocoma ação de Kamoran a 3ppm (indicado pelo fabricante). Obtiveram o mesmo efeito inibidor sobre as bactérias em concentrações que variaram de 50 a 200 ppm de dióxido de cloro. Os autores concluem que o dióxido de cloro deve ser usado com cautela, pois valores maiores que 50 ppm também inibiram a levedura.

\section{Verificação do crescimento de L. mesenteroides em diferentes pHs e temperaturas, em meio CSN}

Quantificação comparativa da viscosidade

Na Figura 4, verifica-se que houve maior diminuição da viscosidade nos pHs 3,0 e 6,0. As maiores diminuições ocorreram quando se utilizou $1,0 \%$ de Poliquilgerm $^{\circledast}(8,52 \%$ em pH 3,0 e 7,07\% em pH 6,0). Em pH 4,0 verificou-se diminuição de 2,69\%. Para as culturas com $0,2 \%$ dePoliquilgerm ${ }^{\circledR}$, verificou-semaior diminuição da viscosidade nos pHs 3,0 e 5,0 (5,98 e $3,20 \%$,respectivamente). Houve um pequenoaumento na viscosidade das culturas com $0,2 \%$ do produto no $\mathrm{pH} 4,0$ e com 1,0\% do produto no $\mathrm{pH} 5,0(0,38 \mathrm{e}$ $0,15 \%$, respectivamente).

A Figura 4indica ainda que L. mesenteroides tem sua atividade metabólica ativa nos pHs de 3,0 a 6,0, na temperatura de $33^{\circ} \mathrm{C}$. Issoexplica a maior formação de dextrana no processo de produção de etanol quando prevalecem essas condições de $\mathrm{pH}$ e temperatura.

Nomesmo experimento, repetidoem temperatura de $28^{\circ} \mathrm{C}$, pode-se verificar na Figura 5 que os maiores valores de diminuição da viscosidade também ocorreram nas culturas em pHs 3,0 e 6,0. Em pH 6,0 foram registrados 16,84 e $16,71 \%$ de diminuição da viscosidadequandoutilizados, respectivamente, $1,0 \mathrm{e} 0,2 \%$ de Poliquilgerm ${ }^{\circledast}$, sendoesteomelhor resultadoemambos os experimentos. Em pH3,0, houve3,24\% de diminui-

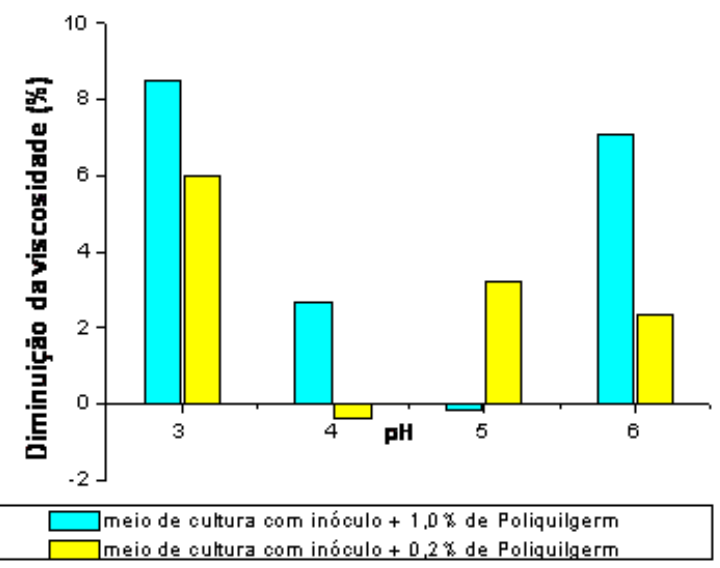

Fig. 4 - Quantificação comparativa da diminuição da viscosidade das culturas de Leuconostoc mesenteroides acrescidas de Poliquilgerm ${ }^{\circledR}$, em diferentes $\mathrm{pHs}$ a $33^{\circ} \mathrm{C}$. ção quando utilizados $0,2 \%$ do produto, e $1,78 \%$ quando utilizados 1,0\%. Em pHs 4,0 e 5,0, os valores encontrados foram baixos, e houve aumento na viscosidade quandoutilizou-se $1,0 \mathrm{e} 0,2 \%$ dePoliquilgerm ${ }^{\circledR} \mathrm{em} \mathrm{pH}$ $5,0(0,54$ e $4,20 \%$, respectivamente).

Os dados de diferentes $\mathrm{pHs}$ e concentrações de Poliquilgerm ${ }^{\circledast}$ foram analisados através da análise de variância. O teste de Tukey, realizado para os dados de ambos os experimentos, revelou que o parâmetro inóculo foi significativo, e a maior média de viscosidade foi encontrada na presença de inóculo $(1,4083$ cp a $33^{\circ} \mathrm{C}$ e 1,4102 cp a $28^{\circ} \mathrm{C}$ ) (Tabela 1 ). Em relação ao parâmetro $\mathrm{pH}$, os valores de viscosidade não diferiram em valores de $\mathrm{pHs} 3,0$ e 4,0 a $33^{\circ} \mathrm{C}$. Por outro lado, os pHs 5,0 e 6,0 diferiram entre si e entre os demais. A $28^{\circ} \mathrm{C}$ os valores de viscosidade não diferiram nos pHs 4,0 e 6,0, assim como nos pHs 5,0 e 6,0. No entanto, houve diferenças entre os valores de viscosidadenos $\mathrm{pHs} 4,0$ e 5,0, e os valores para $\mathrm{pH} 3,0$ diferiram de todos os demais (Tabela 2). Lembrando que esta análise foi realizada a partir dos valores em viscosidade (cp), razão pela qual apresentou resultados que diferem da observação realizada quando se calculou os valores de porcentagem de diminuição da viscosidade.

Oparâmetro concentração dePoliquilgerm ${ }^{\circledast}$ apresentou diferenças significativas para os valores de viscosidade em ambos os experimentos. A $33^{\circ} \mathrm{C}$ a ausência do produto apresentou a maior média de viscosidade $(1,3914 \mathrm{cp})$ diferindo das demais, que não apresentaram diferenças $(1,3744 \mathrm{cp}$ a $0,2 \%$ do produto e 1,3592 a $1,0 \%$ do produto). A $28^{\circ} \mathrm{C}$ a ausência e a presença de 1,0\% de Poliquilgerm ${ }^{\circledR}$ não apresentaram diferenças estatísticas $(1,3904$ cp a $0,0 \%$ e 1,3838 cp a $1,0 \%$ do produto). A presença de $0,2 \%$ de Poliquilgerm $^{\circledast}$ foi significativa para os valores de viscosidade, que foram os menores valores encontrados (1,3539 cp) (Tabela 3).

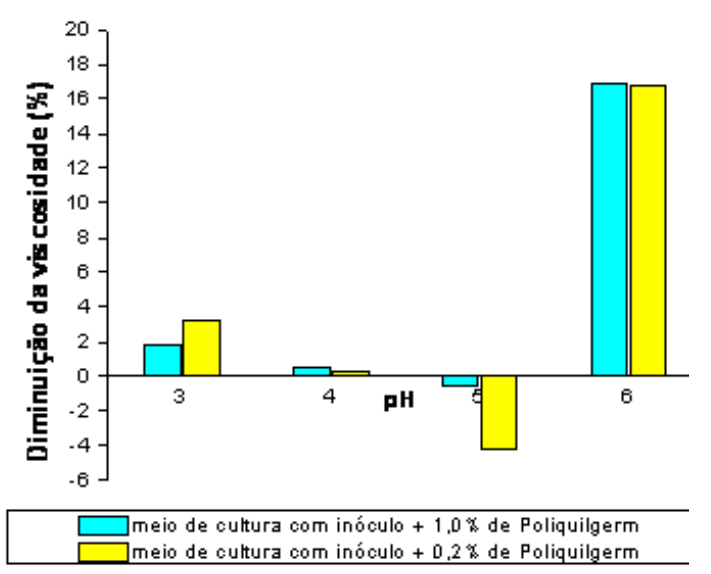

Fig. 5 - Quantificação comparativa da diminuição da viscosidade das culturas de Leuconostoc mesenteroides acrescidas de Poliquilgerm ${ }^{\circledR}$, em diferentes $\mathrm{pHs}$ a $28^{\circ} \mathrm{C}$. 
Embora a análise estatística indique não significância entre a temperatura e viscosidade, as Figuras $4 \mathrm{e} 5$ deixam claro que diferentes $\mathrm{pH}$ e temperaturas podem influenciar a viscosidade do meio.

Tabela 1 - Valores das médias de viscosidade utilizadas na análise estatística (Teste de Tukey), para o parâmetro inóculo.

\begin{tabular}{lcc}
\hline Inóculo & \multicolumn{2}{c}{ Valores de viscosidade $(\mathrm{cp})$} \\
\cline { 2 - 3 } & ${\text { média a } 33^{\circ} \mathrm{C}}$ & média a $28^{\circ} \mathrm{C}$ \\
\hline presente & 1,4083 & 1,4102 \\
ausente & 1,3418 & 1,3418 \\
\hline
\end{tabular}

Tabela 2 - Valores das médias de viscosidade utilizadas na análise estatística (Teste de Tukey), para o parâmetro $\mathrm{pH}$.

\begin{tabular}{ccc}
\hline $\mathrm{pH}$ & \multicolumn{2}{c}{ Valores de viscosidade (cp) } \\
\cline { 2 - 3 } & média a $33^{\circ} \mathrm{C}$ & média a $28^{\circ} \mathrm{C}$ \\
\hline 3,0 & 1,4205 & 1,2843 \\
4,0 & 1,4121 & 1,4322 \\
5,0 & 1,3138 & 1,3821 \\
6,0 & 1,3537 & 1,4055 \\
\hline
\end{tabular}

Tabela 3 - Valores das médias de viscosidade utilizadas na análise estatística (Teste de Tukey), para o parâmetro Concentração.

\begin{tabular}{ccc}
\hline $\begin{array}{c}\text { Concentração do } \\
\text { produto (\%) }\end{array}$ & \multicolumn{2}{c}{ Valores de viscosidade (cp) } \\
\cline { 2 - 3 } & média a $33^{\circ} \mathrm{C}$ & média a $28^{\circ} \mathrm{C}$ \\
\hline 0,0 & 1,3914 & 1,3904 \\
0,2 & 1,3744 & 1,3539 \\
1,0 & 1,3592 & 1,3838 \\
\hline
\end{tabular}

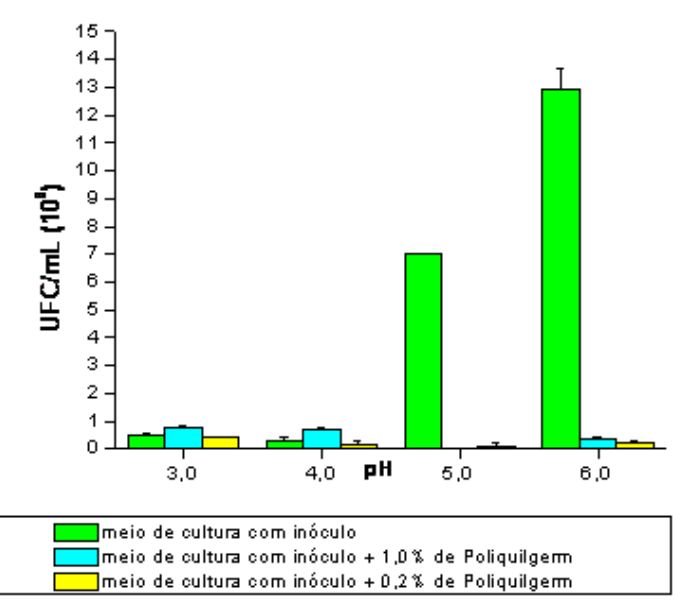

Fig. 6 - Quantificação comparativa da biomassa de Leuconostoc mesenteroides nas concentrações 0,0; 0,2 e 1,0\% de Poliquilgerm ${ }^{\circledR}$, em diferentes $\mathrm{pHs}$ a $33^{\circ} \mathrm{C}$.

\section{Análise da biomassa}

A Figura 6 revela que houve maior crescimento da cultura em pHs 6,0 e 5,0, alcançando 12,95 e 7,00 x $10^{8}$ $\mathrm{UFC} / \mathrm{mL}$, respectivamente.

Houve 97,1 e 100\% de diminuição do crescimento de L. mesenteroides quando utilizados 1,0\% de Poliquilgerm ${ }^{\circledR}$ e 98,1 e $99,8 \%$ para $0,2 \%$ do produto, respectivamente, nos pHs 6,0 e 5,0. Estes resultados evidenciam forte inibição do crescimento de L. mesenteroides pelo Poliquilgerm ${ }^{\circledR}$. Em valores de $\mathrm{pH} 4,0$ e 3,0, o crescimento da bactéria foi menor $\left(0,47\right.$ e $\left.0,30 \times 10^{8} \mathrm{UFC} / \mathrm{mL}\right)$. O pequeno aumento evidenciado na biomassa da cultura quando se adicionou $1,0 \%$ do produto $(0,78$ e 0,73 x $10^{8} \mathrm{UFC} / \mathrm{mL}$ ) pode indicar que o Poliquilgerm ${ }^{\circledR}$ teria ação menos efetiva em meio ácido, na temperatura de $33^{\circ} \mathrm{C}$.

Os resultados para o crescimento da cultura em $28^{\circ} \mathrm{C}$ (Fig. 7) mostram, à semelhança da Figura 6, que houve maior crescimento em $\mathrm{pHs} 6,0$ e 5,0, alcançando 6,73 e 6,86 x $10^{8} \mathrm{UFC} / \mathrm{mL}$, respectivamente.

No pH 6,0 houve $100 \%$ de diminuição do crescimento de L. mesenteroides em ambas as concentrações de Poliquilgerm ${ }^{\circledR}$. Em pH 5,0, houve diminuição de 13,3 e 20,3\% quando utilizados 1,0 e $0,2 \%$ do produto. Nos valores de $\mathrm{pHs} 3,0$ e 4,0, o crescimento foi menor $\left(0,73\right.$ e $\left.0,65 \times 10^{8} \mathrm{UFC} / \mathrm{mL}\right)$. Houve aumento na biomassa da cultura quando se adicionou 1,0\% do produto em $\mathrm{pH} 3,0(2,47 \mathrm{x}$ $10^{8} \mathrm{UFC} / \mathrm{mL}$ ) e quando acrescentou-se $0,2 \%$ do produto em pH 4,0 (0,54 x $\left.10^{8} \mathrm{UFC} / \mathrm{mL}\right)$. Entretanto, são valores menores de crescimento, uma vez que a cultura encontra-se em condições desfavoráveis de $\mathrm{pH}$.

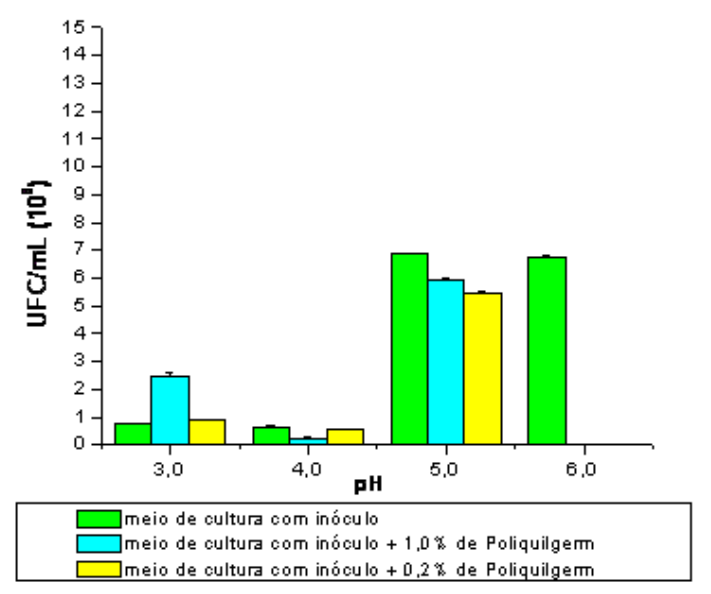

Fig. 7 - Quantificação comparativa da biomassa de Leuconostoc mesenteroides nas concentrações 0,0; 0,2 e 1,0\% de Poliquilgerm ${ }^{\circledR}$, em diferentes $\mathrm{pHs}$ a $28^{\circ} \mathrm{C}$. 
O teste de Tukey realizado para o experimento a $33^{\circ} \mathrm{C}$ mostrou que apenas os pHs 3,0 e 4,0 não diferiram significativamenteem relação à biomassa produzida. A $28^{\circ} \mathrm{C}$ todos os $\mathrm{pHs}$ diferiram entre si, sendo que o maior valor de biomassa foi encontrado em $\mathrm{pH} 5,0$ $\left(6,09 \times 10^{8} \mathrm{UFC} / \mathrm{mL}\right)$. Para o parâmetro concentração de Poliquilgerm ${ }^{\oplus}$, o teste de Tukey mostrou que a ausência do produto foi significativa para o experimento a $33^{\circ} \mathrm{C}$, no entanto não houve diferenças entre as concentrações do produto utilizadas $(1,0 \mathrm{e} 0,2 \%$ de Poliquilgerm $\left.{ }^{\circledast}\right)$. A $28^{\circ} \mathrm{C}$, os resultados foram significativos paras todas as concentrações nos diferentes pHs, sendo quea maior média dos valores debiomassa foram encontradas na ausência do produto $\left(3,74 \times 10^{8}\right.$ UFC $/ \mathrm{mL}$ ), seguida de 1,0 e $0,2 \%$ de Poliquilgerm ${ }^{\circledR}$, respectivamente $\left(2,15\right.$ e $\left.1,72 \times 10^{8} \mathrm{UFC} / \mathrm{mL}\right)$.

Comparando-se os resultados de crescimento de L. mesenteroides nas temperaturas de $33 \mathrm{e} 28^{\circ} \mathrm{C}$, podese inferir que a bactéria tem preferência a temperaturas mais elevadas equeo $\mathrm{pHélimitante.} \mathrm{Ocrescimen-}$ to da bactéria manifestado no $\mathrm{pH} \mathrm{3,0} \mathrm{em} \mathrm{ambas} \mathrm{as}$ temperaturas mostra que a ação do Poliquilgerm ${ }^{\circledR}$ neste $\mathrm{pH}$ tem menor eficiência.

Os melhores resultados deste experimento, em temperaturas de 33 e $28^{\circ} \mathrm{C}$, foram obtidos quando a cultura de L. mesenteroides cresceu em pH 6,0. Neste pHhouve maior produção de biomassa e os melhores valores para diminuição da viscosidade quando aplicado Poliquilgerm ${ }^{\circledast}\left(28^{\circ} \mathrm{C}\right)$. Nestes experimentos em pHs mais baixos a bactéria tem menor tolerância e produz menos biomassa. No entanto, em temperatura de $33^{\circ} \mathrm{C}$, verificou-se os melhores resultados de diminuição da viscosidade em pH 3,0 (Fig. 4), mesmo a bactéria produzindo pouquíssima biomassa (Fig. 6). Uma hipótese é a de que o micro-organismo em condições desfavoráveis de $\mathrm{pH}$ seja estimulado para sua defesa em aumentar a produção de dextrana e, consequentemente, a viscosidade do meio de cultura.

BREGAGNOLI (2006) verificou que a própolis apresentou o mesmo efeito que a ampicilina quando aplicada com finalidade de combater a contaminação por microrganismosna produçãode cachaça. Dessemodo, a aplicação de biocidas naturais para combater contaminações em indústrias de fermentação mostra-se potencialmente viável, já que podem ser uma alternativa em substituição aos biocidas já utilizados, economicamente mais onerosos.

Bertoletti (2008) verificou que o produto Poliquilgerm ${ }^{\circledR}$ apresenta açãobiocida sobre S.cerevisiae apenas quando utilizado na concentração de 200 ppm, sendo que até a concentração de 1 ppm a viabilidade da levedura não é afetada a níveis significativos nas primeiras 24 horas. Em L. fermentum o produto mostrou ação bactericida na concentração de 50 ppm. Com 24horas detempo de contatonesta concentração a inviabilização do crescimento celular foi total. A autora conclui queo Poliquilgerm ${ }^{\circledR}$ pode ser efetivono controle de L.fermentum e debactérias contaminantes da fermentação etanólica, uma vez que a diminuição na produção de ácido lático atingiu cerca de $50 \%$ na concentração de 0,5 ppm dobiocida e $90 \%$ em 20 ppm. Além disso, verificou que o rendimento alcoólico não é prejudicado com a adição do produto.

\section{CONCLUSÕES}

O acréscimo de 0,$2 ; 1,0$ e 2,0\% de Poliquilgerm ${ }^{\circledR}$ provocou diminuição da viscosidade das culturas de L. mesenteroides após 24 horas, tanto em meio Mayeux eColmer comoem meioCSN. Verificou-seinibiçãodo crescimento da bactéria quando se utilizou a menor concentração do produto $(0,2 \%)$ após as primeiras 6 horas, e após 20 horas em contato com 1,0 e 0,2\% de Poliquilgerm ${ }^{\circledR}$.Em meio de cultivocom $\mathrm{pH} 3,0 \mathrm{e} 4,0, \mathrm{~L}$. mesenteroides sofre menor inibição do crescimento em 28 e $33^{\circ} \mathrm{C}$, evidenciando ação menos efetiva do produto sobre a bactéria em valores de $\mathrm{pH}$ baixos.

Estes resultados mostram que o produto Poliquilgerm ${ }^{\circledR}$ podevir a ser uma alternativa nocontrole de contaminações por L. mesenteroides em indústrias sucroalcooleiras, já que se mostrou eficaz no controle do crescimento da bactéria nas primeiras 6 horas. A diminuiçãoda viscosidade também assumeimportância na medida em que os experimentos evidenciaram ação do produto em valores de $\mathrm{pH} 3,0$, condição frequente no processo de fermentação do etanol.

\section{AGRADECIMENTOS}

AoConselho Nacional de DesenvolvimentoCientífico Tecnológico (CNPq), pela bolsa concedida e ao GrupodeQuímica Analíticae Tecnologia dePolímeros (GQATP) do Instituto de Química da USP de São Carlosque, coordenadopeloProf.Dr.GilbertoOrivaldo Chierice, gentilmente cedeu o produto para a realização deste trabalho.

\section{REFERÊNCIAS}

BERTOLETTI, A.C.D.; SANTOS, A.M.; ANGELIS, D.F.; CHIERICE, G.O.; CLARO NETO, S. Viabilidade de Candida albicans CCT 0776 in vitro sob atividade antimicrobiana do Poliquilgerm ${ }^{\circledast}$ derivado do óleo de Ricinus communis L. (mamona). In: ENCONTRO DE BIÓLOGOSDOCONSELHOREGIONAL DE BIOLOGIA - 1, 15., 2004, São Pedro. Resumos. São Pedro: 2004. p.142. res. 11.28 .

BERTOLETTI, A.C.D. Ação biocida do Poliquilgerm ${ }^{\circledR}$ derivado do óleo de Ricinus communis L. (mamona) sobre 
bactérias contaminantes da fermentação etanólica. 2008. 74f. Dissertação (Mestrado em Microbiologia Aplicada) Instituto de Biociências, Universidade Estadual Paulista, Rio Claro, 2008.

BOLSON, J.; SCHOSSLER, J.E.; ORNES, R.C.; MOTTIN, V.; ALBERTI, T. Análise clínica, radiológica, macroscópica e histológica do úmero de codornas domésticas (Coturnix japonica), submetido ao implante da poliuretana derivada do polímero de mamona (Ricinnus communis). Ciência Rural, v.35, n.5, p.1123-1130, 2005.

BREGAGNOLI, F.C.R. Comportamento fisiológico de microrganismos submetidos a biocidas convencional e natural na produção de cachaça. 2006. 69f. Tese (Doutorado em Microbiologia Agropecuária) - Faculdade de Ciências Agrárias e Veterinárias, Universidade Estadual Paulista, Jaboticabal, 2006.

CHIERICE, G.O.; CLARO-NETO, S. Aplicação industrial do óleo. In: AZEVEDO, D.M.P.; LIMA, E.F. (Ed.). O agronegócio da mamona no Brasil. Brasília: Embrapa, 2001. cap.5.

FERREIRA, C.M. Atividade antimicrobiana. Estudo "in vivo" da atividade antimicrobiana do gel de papaina a 0,4\%, detergente de mamona a 10\%, hipoclorito de sódio a 0,5\% utilizados como soluções irrigantes em Endodontia. 1996. 85f. Monografia (Residência em Endodontia) - Faculdade de Odontologia de Ribeirão Preto, Universidade de São Paulo, Ribeirão Preto, 1996.

GALLO, C.R. Determinação da microbiota bacteriana de mosto e de dornas de fermentação alcoólica. 1989. 388 f. Tese (Doutorado em Ciências de Alimentos) - Faculdade de Engenharia de Alimentos da Universidade Estadual de Campinas, Campinas, 1989.

GUERRA, E.J. Isolamento de bactérias contaminantes da fermentação etanólica que induzem a floculação de Saccharomyces cerevisiae e sua sensibilidade a agentes antimicrobianos. 1995. 150 f. Dissertação (Mestrado em Microbiologia Aplicada) - Instituto de Biociências, Universidade Estadual Paulista, Rio Claro, 1995.

HOLT, J.G.; MAIR, N.S.; SHARPE, M.E.; SNEATH, P.H.A. Bergey's manual of systematic bacteriology. Baltimore: Williams \& Wilkins, 1986. v.2.

LEONARDO, M.R.; SILVA, L.A.B.; FILHO, M.T.; BONIFÁCIO, K.C.; ITO, I.Y. In vitro evaluation of the antimicrobial activity of a castor oil-based irrigant. Journal of Endodontics, v.27, n.12, p.717-719, 2001.

LUDWIG, K.M. Floculação de Saccharomyces cerevisiae caracterização e ação de enzimas desfloculantes. 1998. 134f. Dissertação (Mestrado em Microbiologia Aplicada) Instituto de Biociências, Universidade Estadual Paulista, Rio Claro, 1998.

MAYEUX, J.V.; COLMER, A.R. Selective medium for Leuconostoc detection. Journal of Bacteriology, v.81, n.6, p1009-1011, 1961.
MENEGHIN, S.P.; REIS, F.C.; ALMEIDA, P.G.; CECCATO-ANTONINI, S.R. Avaliação do emprego de dióxido de cloro como antibacteriano na fermentação alcoólica. In: SIMPÓSIO NACIONAL DE BIOPROCESSOS, 16., 2007. Curitiba. Anais. Curitiba: 2007. 7p. 1 CD ROM.

MESSETTI, M.A.;SANTOS, A.M.;ANGELIS, D.F.;DALFRÉ, I.A.B.; CHIERICE, G.O.; CLARO NETO, S. Viabilidade de Escherichia coli CCT 1457 in vitro sob atividade antimicrobiana do Poliquilgerm ${ }^{\circledR}$ derivado do óleo de Ricinus communis L. (mamona). In: WORKSHOP INTERNACION ALSOBREMICROBIOLOGIA AMBIENTAL-“DESAFIOSEOPORTUNIDADESNA AMÉRICA DO SUL", 2005, Campinas. Resumos. Campinas: Universidade Estadual de Campinas, 2005. 1 CD-ROM.

OLIVA-NETO, P.; YOKOYA, F. Susceptibility of Saccharomyces cerevisiae and lactic acid bacteria from the alcohol industry to several antimicrobial compounds. Brazilian Journal of Microbiology, v.32, p.10-14, 2001.

OLIVEIRA, M.G.R. Estudo da decomposição de sacarose por hidrólise utilizando uma mistura de ésteres derivados do óleo de mamona. 2005. 98f. Dissertação (Mestrado em Química Analítica) - Instituto de Química de São Carlos, Universidade de São Paulo, São Carlos, 2005.

REZENDE, C.M.F.; SILVA, M.C.; LARANJEIRA, M.G.; BORGES, A.P.B. Estudo experimental do poliuretano de óleo de mamona (Ricinus communis) como substituto parcial do tendão calcâneo comum em coelhos (Oryctolagus cuniculus). Arquivo Brasileiro de Medicina Veterinária e Zootecnia, v.53, n.6, p.695-700, 2001.

RODINI, M.A.T. Isolamento, caracterização e identificação de bactérias contaminantes de dornas de fermentação nas destilarias de etanol. 1985. 92f. Dissertação (Mestrado em Microbiologia Agrícola) - Escola Superior de Agricultura "Luiz de Queiroz", Universidade de São Paulo, Piracicaba, 1985.

ROSALES, S.Y.R. Contaminantes bacterianos da fermentação etanólica: isolamento em meios diferenciais, identificação e avaliação de desinfetantes. 1989. 200 f. Tese (Doutorado em Biologia Vegetal) - Instituto de Biociências, Universidade Estadual Paulista, Rio Claro, 1989.

SILVA FILHO, E.A. Fermentação etanólica: influência do ácido sulfúrico sobre a viabilidade da levedura de processo e bactérias e leveduras contaminantes. 1993. 65f. Dissertação (Mestrado em Microbiologia Aplicada) - Instituto de Biociências, Universidade Estadual Paulista, Rio Claro, 1993.

STUPIELLO, M. G. Avaliação de metodologia para estudo da ação de alguns antimicrobianos frente às bactérias gram (+) isoladas da fermentação alcoólica. 1993. 96f. Dissertação (Mestrado em Ciências e Tecnologia de Alimentos), Escola Superior de Agricultura "Luiz de Queiroz", Universidade de São Paulo, Piracicaba, 1993.

Recebido em 5/2/09

Aceito em $14 / 4 / 10$ 